\title{
The chemical and isotopic compositions of thermal waters and gases in the Republic of Buryatia, Russia
}

\author{
Elena Zippa ${ }^{1,2, *}$, Alexey Plyusnin ${ }^{3}$, and Stepan Shvartsev ${ }^{1,2}$ \\ ${ }^{1}$ Tomsk Branch of the Trofimuk Institute of Petroleum Geology and Geophysics SB RAS, Tomsk, \\ Russia \\ ${ }^{2}$ National Research Tomsk Polytechnic University, Tomsk, Russia \\ ${ }^{3}$ Geological Institute Siberian Branch Russian Academy of Sciences, Russia
}

\begin{abstract}
The chemical and isotopic compositions of waters and associated gases in the Republic of Buryatia are investigated in this report. Results show the thermal waters are predominantly enriched in $\mathrm{N}_{2}$. They are alkaline, low salinity and have high concentrations of $\mathrm{HCO}_{3}{ }^{-}, \mathrm{SO}_{4}^{2-}, \mathrm{F}$, Si but low values for $\mathrm{Ca}^{2+}, \mathrm{Mg}^{2+}, \mathrm{K}^{+}$. According to isotopic composition, the thermal waters are meteoric in origin. Despite the low salinity, the thermal waters are in equilibrium with calcite, magnesite, fluorite, albite, laumontite and other minerals but are not equilibrium with respect to primary aluminosilicates. This indicates that the thermal waters and waterbearing rocks represent the equilibrium-nonequilibrium system.
\end{abstract}

\section{Introduction}

Thermal waters are distributed around the world, especially within tectonically active areas, and attract the attention of many scientists. The most discussed issues in case of thermal waters include the processes and mechanism of their formation, depths of circulation, trace-element geochemistry, processes of their interaction with water-bearing rocks, thermodynamic equilibrium with different minerals, and genesis of secondary minerals.

The thermal waters of the studied region were considered previously [1-3]. The papers are dedicated to chemical composition peculiarities and the saturation state with different minerals of the thermal waters in the Baikal rift zone in general.

The updated data for the thermal waters, particularly in the Republic of Buryatiya, is presented in the current manuscript. The manuscript is aimed at the detailed investigation of the thermal waters' composition and equilibrium with the main minerals of water-bearing rocks for the further identification of the mechanisms and processes of their formation.

\footnotetext{
*Corresponding author: zev-92@mail.ru
} 


\section{Site description}

The Republic of Buryatia is located in the south-central region of Siberia, Russia (Fig. 1) along the eastern shore of Lake Baikal. Geologically the territory is located within the frameworks of the Baikal Rift Zone. It is the largest zone in Eurasia and the second largest continental zone and thermal waters of different compositions are widespread. The Baikal Rift Zone is located at the boundary between the Precambrian Siberian Platform and the Transbaikalian folded area and differs from the surrounding areas in the abundance of deep faults that resulted

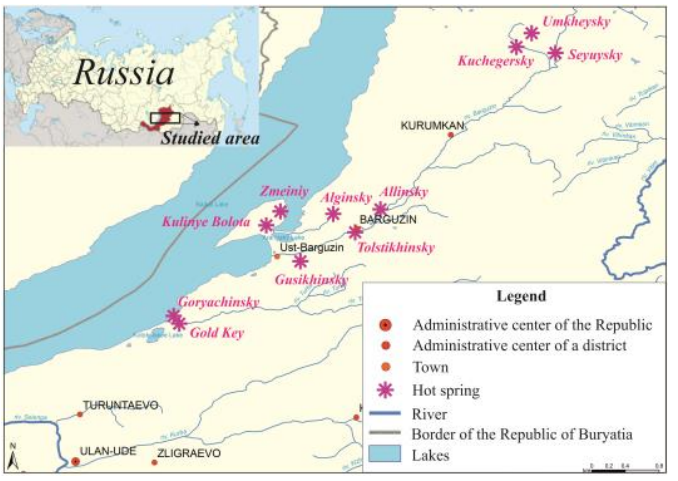

Fig. 1. Location of hot springs in the Republic of Buryatia. from rifting processes. The faults, with their water penetrate to depths of $12-15 \mathrm{~km}$, based on data of electrometric monitoring [4].

The Baikal Rift Zone within the Republic of Buryatiya is composed mainly of intrusive rocks where the thermal waters' discharge zones are located. The waters occur in Barguzin complex represented by intrusive rocks of Proterozoic age. The Barguzin complex of granitoids consists of two phases: (1) medium-grained porphyritic (often, gneissoid) biotitic, biotite-hornblende, and hornblende granites, granosyenites, granodiorites, syenites, and diorites and (2) medium- and fine-grained massive and gneissoid (sometimes, porphyritic) biotitic granites [1].

\section{Materials and methods}

This research is based on the results of hydrogeochemical sampling that was conducted in 2016. The thermal springs were sampled for chemical, gas and isotopic compositions. The rapidly changing parameters: $\mathrm{pH}$, temperature, and electrical conductivity, were determined in-situ by using an AMTAST AMT03 (USA) device. The samples were filtered in the field using a $0.45 \mu \mathrm{m}$ membrane filter. The major chemical elements were determined by a titration method with a liquid analyzer "Anion 7-51" (Russia) and ion chromatography with a Dionex chromatograph ICS-00 (USA). The water isotopic analysis (D, $\left.{ }^{18} \mathrm{O}\right)$ was conducted by using an isotope mass spectrometer with a TC/EA-IRMS element analyzer (Finnigan MAT 253, Thermo Scientific, USA). The free gas composition was determined by gas chromatography, with chromatograph "Khromos-GKh-1000".

Analyses were conducted in certified laboratories. The analysis for major elements composition was carried out in The Problem Research Laboratory of Hydrogeochemistry (TPU, Tomsk), the isotopic composition - in the Center for Chemical Analysis and Physical Testing (ECUT, Nanchang, China) and free gas composition - in the laboratory of Production and Geological Company "Sibgeocom" (Irkutsk, Russia).

The saturation states of the thermal waters with primary and secondary minerals were calculated using the Geochemist's Workbench software [5] at the springs' temperature. The saturation index $(\mathrm{SI})$ is defined as

$$
S I=\log (Q / K)
$$

where $\mathrm{Q}$ is the reaction quotient (or ion activity product) and $\mathrm{K}$ is the equilibrium constant at a given temperature and pressure. In the case when $\mathrm{SI}=0$ water is in equilibrium with the mineral and no dissolution or precipitation should take place. SI $>0$ indicates that 
the solution is supersaturated with respect to a given mineral; $\mathrm{SI}<0$ indicates undersaturation.

\section{The chemical and isotopic composition of water and gas}

The gas data show the type of thermal waters of the Republic of Buryatia change from $\mathrm{CH}_{4}-\mathrm{N}_{2}$ to $\mathrm{N}_{2}$, but are predominantly enriched with nitrogen that comprises 35 to 99 vol.\% (Table 1). The hot springs with $\mathrm{N}_{2}$ exceeding 85 vol.\% refer to the $\mathrm{N}_{2}$-rich thermal waters. However, there are two springs where $\mathrm{CH}_{4}$ is the dominant gas comprising 61-62 vol.\% and nitrogen values are below 40 vol.\%. These two springs belong to the $\mathrm{CH}_{4}-\mathrm{N}_{2}$ thermal waters. The content of other gases does not exceed 1 vol.\% except for $\mathrm{O}_{2}$ and $\mathrm{CO}_{2}$, with values that reach 7 and 3 vol.\%, respectively.

Table 1. The gas composition of the thermal (vol.\%) waters in the Republic of Buryatia.

\begin{tabular}{|c|c|c|c|c|c|c|c|}
\hline № & Hot spring & $\mathbf{N}_{\mathbf{2}}$ & $\mathbf{O}_{\mathbf{2}}$ & $\mathbf{C O}_{\mathbf{2}}$ & $\mathbf{H}_{\mathbf{2}}$ & $\mathbf{H e}$ & $\mathbf{C H}_{\mathbf{4}}$ \\
\hline $16-7$ & Alginsky & 34.8 & 0.60 & 1.98 & 0.000529 & 0.01 & 62.0 \\
\hline $16-10$ & Kuchigersky & 37.9 & 0.58 & 0.00 & 0.000212 & 0.02 & 60.9 \\
\hline $16-6$ & Tolstikhinsky & 86.1 & 0.43 & 0.00 & 0.000209 & 0.08 & 12.7 \\
\hline $16-3$ & Kulinye Bolota & 87.7 & 0.55 & 0.00 & 0.000264 & 0.11 & 10.9 \\
\hline $16-5$ & Gusikhinsky & 89.5 & 7.09 & 2.92 & 0.000339 & 0.08 & 0.01 \\
\hline $16-11$ & Seuisky & 98.4 & 1.01 & 0.00 & 0.000346 & 0.11 & 0.00 \\
\hline $16-9$ & Umkheysky & 98.7 & 0.51 & 0.00 & 0.000402 & 0.12 & 0.17 \\
\hline $16-4$ & Zmeiny & 98.9 & 0.45 & 0.00 & 0.000235 & 0.16 & 0.14 \\
\hline
\end{tabular}

The chemical composition data (Table 2) show that the salinity of the thermal waters from 453 to $858 \mathrm{mg} / \mathrm{L}$. Despite the low TDS, the thermal waters are alkaline, with $\mathrm{pH}$ values of 8.19-9.66. The high $\mathrm{pH}$ and low salinity are typical for the $\mathrm{N}_{2}$-rich thermal waters but unusual for the majority of natural waters. The explanation for this is discussed in details in $[1,3,6]$, but it should be briefly mentioned that this results from $\mathrm{OH}^{-}$formed by the hydrolysis of aluminosilicate minerals and the absence of alkalinity neutralizing acids.

Table 2. The chemical composition (mg/L) of the thermal waters in the Republic of Buryatia.

\begin{tabular}{|c|c|c|c|c|c|c|c|c|c|c|c|c|c|c|c|}
\hline No & Hot spring & $\begin{array}{c}\mathbf{T}, \\
{ }^{\circ} \mathbf{C}\end{array}$ & $\mathbf{p H}$ & $\begin{array}{c}\mathbf{E h}, \\
\mathbf{m V}\end{array}$ & $\mathbf{T D S}$ & $\mathbf{C O}_{3}{ }^{2-}$ & $\mathbf{H C O}_{3}$ & $\mathbf{S O}_{4}{ }^{2-}$ & $\mathbf{C l}^{-}$ & $\mathbf{C a}^{2+}$ & $\mathbf{M g}^{2+}$ & $\mathbf{N a}^{+}$ & $\mathbf{K}^{+}$ & $\mathbf{S i O}_{2}$ & $\mathbf{F}^{-}$ \\
\hline $16-1$ & Goryachinsky & 51 & 9.03 & -206 & 685 & 15.6 & 42 & 365 & 6.2 & 34.7 & 2.44 & 149 & 4.34 & 63 & 3.0 \\
\hline $16-2$ & Gold Key & 45 & 8.80 & -110 & 526 & 10.0 & 60 & 210 & 19.6 & 12.9 & 1.22 & 123 & 4.21 & 78 & 6.9 \\
\hline $16-3$ & Kulinye Bolota & 51 & 9.40 & -115 & 628 & 25.8 & 137 & 133 & 32.6 & 2.1 & 0.73 & 154 & 3.40 & 121 & 19.0 \\
\hline $16-4$ & Zmeiniy & 37 & 9.55 & -350 & 582 & 25.2 & 144 & 122 & 40.5 & 4.4 & 0.24 & 146 & 2.24 & 88 & 9.1 \\
\hline $16-5$ & Gusikhinsky & 72 & 8.47 & 38 & 858 & 9.4 & 106 & 356 & 33.5 & 17.2 & 0.98 & 211 & 12.00 & 101 & 10.9 \\
\hline $16-6$ & Tolstikhinsky & 29 & 9.66 & -240 & 453 & 19.5 & 128 & 92 & 20.8 & 3.2 & 1.22 & 114 & 2.50 & 62 & 9.5 \\
\hline $16-7$ & Alginsky & 21 & 8.19 & 124 & 664 & 3.0 & 63 & 338 & 15.5 & 81.7 & 1.59 & 104 & 5.63 & 47 & 4.4 \\
\hline $16-8$ & Allinsky & 43 & 9.22 & -339 & 556 & 28.5 & 154 & 88 & 14.3 & 8.6 & 0.73 & 122 & 4.31 & 125 & 11.5 \\
\hline $16-9$ & Umkheysky & 48 & 9.50 & -275 & 506 & 42.0 & 134 & 79 & 12.4 & 1.7 & 0.85 & 125 & 1.90 & 95 & 14.4 \\
\hline $16-10$ & Kuchegersky & 38 & 9.51 & -300 & 465 & 29.4 & 110 & 90 & 15.0 & 2.3 & 0.92 & 118 & 1.51 & 86 & 12.0 \\
\hline $16-11$ & Seyuysky & 53 & 9.38 & -244 & 456 & 35.7 & 100 & 85 & 11.0 & 2.0 & 0.31 & 130 & 1.55 & 72 & 19.0 \\
\hline
\end{tabular}

The redox (Eh) predominantly ranges from -350 to $-110 \mathrm{mV}$ but there are two hot springs, 16-5 and 16-7, where Eh values are respectively 38 and $124 \mathrm{mV}$. These springs are with high $\mathrm{O}_{2}$ content in the gas. The temperature of the thermal waters varies from 21 to $72{ }^{\circ} \mathrm{C}$. Two hot springs are located next to rivers, therefore, their temperature (21 and 29 ${ }^{\circ} \mathrm{C}$ ) is lower, probably because of the mixing with colder waters.

The chemical composition is characterized by clear competition between $\mathrm{SO}_{4}{ }^{2-}$ and $\mathrm{HCO}_{3}{ }^{-}$among anions. The concentration of $\mathrm{SO}_{4}{ }^{2-}$ and alkalinity- ranging respectively from 
79 to $365 \mathrm{mg} / \mathrm{L}$ and from 69 to $218 \mathrm{mg} / \mathrm{L}$. The $\mathrm{Cl}^{-}$content is lower, 6.2-40.5 mg/L. Among cations, $\mathrm{Na}^{+}$is dominant except for Alginsky hot spring, where $\mathrm{Ca}^{2+}$ values are higher. The concentrations of $\mathrm{Na}^{+}$vary from 104 to $211 \mathrm{mg} / \mathrm{L}$. The concentrations of $\mathrm{Mg}^{2+}$ and $\mathrm{K}^{+}$are low and do not exceed respectively 2.5 and $6 \mathrm{mg} / \mathrm{L}$, excluding the Gusikhhinskiy hot spring where $\mathrm{K}^{+}$content reaches $12 \mathrm{mg} / \mathrm{L}$. The thermal waters of the Republic of Buryatia are significantly enriched in $\mathrm{F}^{-}$and $\mathrm{SiO}_{2}$ with concentrations ranging respectively from 3 to $19 \mathrm{mg} / \mathrm{L}$ and from 47 to $125 \mathrm{mg} / \mathrm{L}$. To summarize, the thermal waters investigated change from $\mathrm{HCO}_{3}-\mathrm{SO}_{4}-\mathrm{Na}$ to $\mathrm{SO}_{4}-\mathrm{Na}$ through $\mathrm{SO}_{4}-\mathrm{HCO}_{3}-\mathrm{Na}$ type waters (Fig. 2).

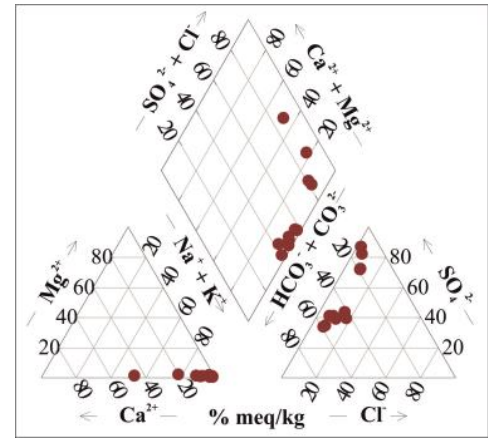

Fig. 2. The Piper diagram for the thermal waters of the Republic of Buryatia.

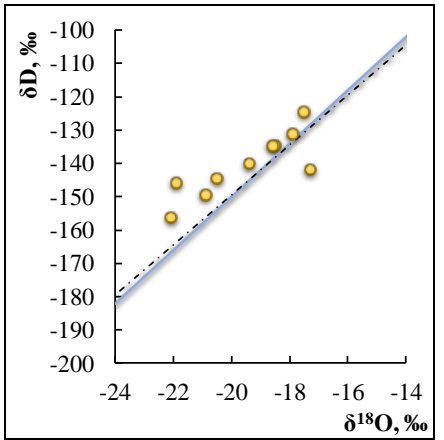

Fig. 3. Isotopic composition of the thermal waters in the Republic of Buryatia.

The isotopic composition of the thermal waters was studied to determine their genetic type. The data obtained and isotopic composition of the region's precipitation [7] show that the thermal waters plot along the local meteoric water line (Fig. 3). Therefore, the thermal waters of the Republic of Buryatia are meteoric in their origin. The isotopic composition is characterized by very low content of $\mathrm{D}$ and ${ }^{18} \mathrm{O}$ that respectively ranges from - 156 to $124 \%$ and from -22.1 to $-17.3 \%$. It can be explained by the waters originating within glacial deposits with a much lighter isotopic composition [8].

\section{The thermal waters equilibrium with minerals of water-bearing rocks}

Results of the thermodynamic calculation show that the thermal waters of the Republic of Buryatia are in equilibrium with some minerals and are not in equilibrium with others. To consider the saturation state of the thermal waters with carbonate minerals, it is shown in the Fig. 4 that despite low salinity and low content of $\mathrm{Ca}^{2+}$ and $\mathrm{Mg}^{2+}$ the waters are saturated with calcite (Fig. 4a) and magnesite (Fig. 4b). The equilibrium with calcite and dolomite becomes a geochemical barrier which limits the accumulation of $\mathrm{Ca}^{2+}$ and $\mathrm{Mg}^{2+}$ in these waters.

The thermal waters also achieved equilibrium with fluorite and saturation with fluorite is attained at lower temperatures than to carbonates (Fig. 4c). We will not focus on the fluorine's sources and its accumulation mechanisms in details because it was considered previously $[6,9]$. But briefly mention that the high concentration of $\mathrm{F}^{-}$in the studied thermal waters are the result of aluminosilicate hydrolysis and relatively low Ca values. 

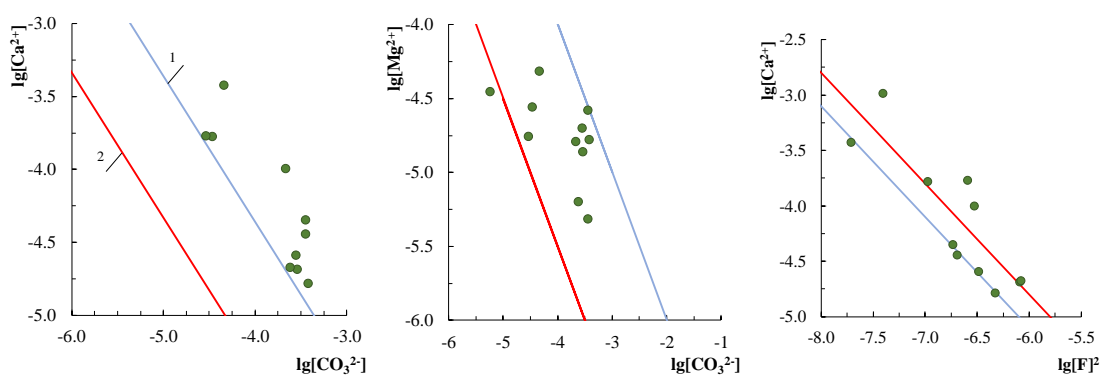

Fig. 4. The equilibrium of thermal waters with calcite (a), magnesite (b) and fluorite (c) at $25^{\circ} \mathrm{C}$ (line 1$)$ and $100{ }^{\circ} \mathrm{C}$ (line 2).

Contrary to the saturation with carbonate minerals, the thermal waters of the Republic of Buryatia exhibited more complex saturation states with respect to aluminosilicate minerals (Fig. 5). The thermal waters are saturated with albite, laumontite, microcline, glaucophane, chlorite and other minerals. But the thermal waters were not at equilibrium with primary aluminosilicate minerals, including anorthite, analcime, and forsterite.
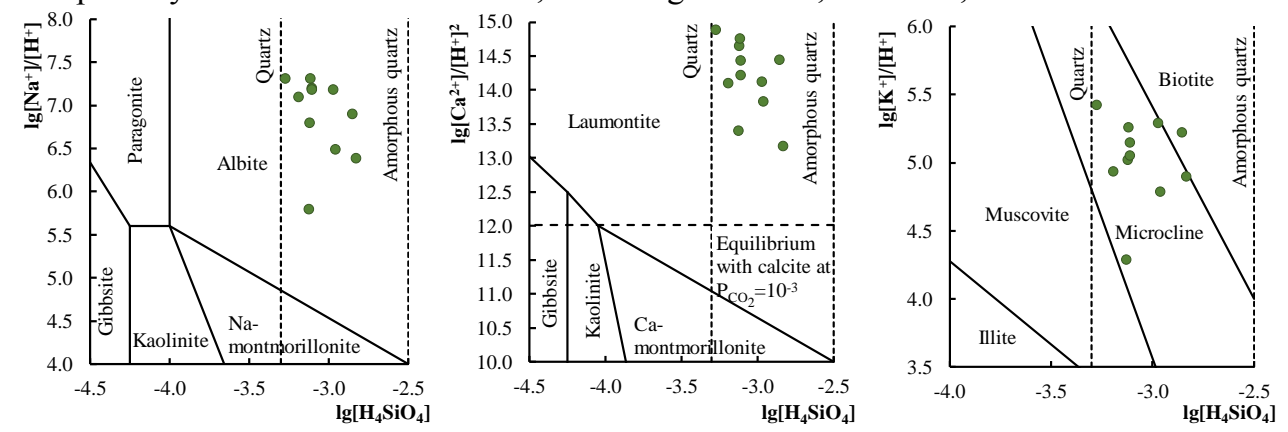

Fig. 5. Saturation states of the thermal waters with aluminosilicate minerals: (a) $\mathrm{HCl}-\mathrm{H}_{2} \mathrm{O}-$ $\mathrm{Al}_{2} \mathrm{O}_{3}-\mathrm{Na}_{2} \mathrm{O}-\mathrm{SiO}_{2}$ system at $100^{\circ} \mathrm{C}$; (b) $\mathrm{HCl}-\mathrm{H}_{2} \mathrm{O}-\mathrm{Al}_{2} \mathrm{O}_{3}-\mathrm{CaO}-\mathrm{SiO}_{2}$ system at $100^{\circ} \mathrm{C}$; (c) $\mathrm{SiO}_{2}-\mathrm{Al}_{2} \mathrm{O}_{3}-\mathrm{K}_{2} \mathrm{O}-\mathrm{CO}_{2}-\mathrm{H}_{2} \mathrm{O}$ system at $100^{\circ} \mathrm{C}$.

\section{Conclusion}

In the Republic of Buryatia, thermal waters are widely distributed. They are meteoric, $\mathrm{HCO}_{3}-\mathrm{SO}_{4}-\mathrm{Na}$ and $\mathrm{SO}_{4}-\mathrm{Na}$, predominantly enriched with $\mathrm{N}_{2}$ gas, alkaline, with low TDS, high concentrations of $\mathrm{HCO}_{3}^{-}, \mathrm{SO}_{4}{ }^{2-}, \mathrm{F}^{-}, \mathrm{Si}$ and low content of $\mathrm{Ca}^{2+}, \mathrm{Mg}^{2+}, \mathrm{K}^{+}$. The thermal waters and water-bearing rocks represent a unique equilibrium-nonequilibrium system. The thermal waters are undersaturated with minerals which continuously dissolve, including anorthite, analcime, and forsterite, but are at equilibrium with respect to other minerals which form at the same time, including calcite, magnesite, fluorite, albite, laumontite, microcline, glaucophane, and chlorite [9].

This study was made under the support of Russian science foundation, grant №. 17-17-01158 and was funded by RFBR according to the research project № 18-55-80015

\section{References}

1. A.M. Plyusnin, L.V. Zamana, S.L. Shvartsev, O.G. Tokarenko, M.K. Chernyavskii, Geol. Geophys., 54 (5), 647-664 (2013) 
2. S.L. Shvartsev, Bull. of the Tomsk Polyt. Univ., 328 (12), 105-115 (2017)

3. S.L. Shvartsev, L.V. Zamana, A.M. Plyusnin, O.G. Tokarenko, Geochem. Int., 53 (8), 713-725 (2015).

4. E.V. Pinneker, A.M. Popov, E.B. Shpynev, Dokl. Akad. Nauk., 359 (3), 397-400 (1998)

5. C.M. Bethke, B. Farrell, S. Yeakel, LLC, Champaign, Illinois, US. (2018)

6. S.L. Shvartsev, Z. Sun, S.V. Borzenko, B. Gao, O.G. Tokarenko, E.V. Zippa, Appl. Geoch., 96, 113-130 (2018)

7. Ju.N. Chizhova, J. Yu. Vasilchuk, K. Yoshikawa, N.A. Budantseva, D. L. Golovanov, O.I. Sorokina, Ju.V. Stanilovskaya, Yu.K. Vasil'chuk, Ice and Snow, 55 (3), 55-65 (2015)

8. V.I. Ferronsky, V.A. Polyakov, Springer, Berlin, 567 (2012)

9. S.L. Shvartsev, Geochem. Int., 46 (13), 1285-1398 (2008) 